\title{
The Effect of Cu Content and Surface Finish on the Metal Dusting Resistance of Additively Manufactured NiCu Alloys
}

\author{
Katrin Jahns ${ }^{1,2}$ - Anke S. Ulrich ${ }^{3} \cdot$ Clara Schlereth $^{3} \cdot$ Lukas Reiff $^{1}$. \\ Ulrich Krupp ${ }^{1} \cdot$ Mathias C. Galetz ${ }^{3}$
}

Received: 26 May 2021 / Revised: 26 May 2021 / Accepted: 27 May 2021 /

Published online: 28 June 2021

(c) The Author(s) 2021

\begin{abstract}
Due to the inhibiting behavior of $\mathrm{Cu}, \mathrm{NiCu}$ alloys represent an interesting candidate in carburizing atmospheres. However, manufacturing by conventional casting is limited. It is important to know whether the corrosion behavior of conventionally and additively manufactured parts differ. Samples of binary $\mathrm{NiCu}$ alloys and Monel Alloy 400 were generated by laser powder bed fusion (LPBF) and exposed to a carburizing atmosphere $\left(20\right.$ vol\% $\left.\mathrm{CO}-20 \% \mathrm{H}_{2}-1 \% \mathrm{H}_{2} \mathrm{O}-8 \% \mathrm{CO}_{2}-51 \% \mathrm{Ar}\right)$ at $620{ }^{\circ} \mathrm{C}$ and $18 \mathrm{bar}$ for $960 \mathrm{~h}$. Powders and printed samples were investigated using several analytic techniques such as EPMA, SEM, and roughness measurement. Grinding of the material after building (P1200 grit surface finish) generally reduced the metal dusting attack. Comparing the different compositions, a much lower attack was found in the case of the binary model alloys, whereas the technical Monel Alloy 400 showed a four orders of magnitude higher mass loss during exposure despite its $\mathrm{Cu}$ content of more than $30 \mathrm{wt} \%$.
\end{abstract}

Keywords Surface finish $\cdot$ Metal dusting $\cdot \mathrm{NiCu}$ alloys $\cdot$ Monel alloy $400 \cdot$ Additive manufacturing $\cdot$ Laser powder bed fusion

Katrin Jahns

katrin.jahns@iehk.rwth-aachen.de

Anke S. Ulrich

silvia.ulrich@dechema.de

1 IEHK Steel Institute, RWTH Aachen University, Aachen, Germany

2 Faculty of Engineering and Computer Science, University of Applied Sciences Osnabrück, Osnabrück, Germany

3 DECHEMA-Forschungsinstitut, Frankfurt am Main, Germany 


\section{Introduction}

Among the efforts toward climate-neutral technologies, processes that allow the chemical conversion of $\mathrm{CO}_{2}$ and hydrogen are becoming increasingly important. Examples are the newly developed dry reforming process, in which $\mathrm{CO}_{2}$ and methane can be converted to $\mathrm{CO}$-rich synthesis gas at high pressures and high temperatures [1-4]. The synthesis gas in turn is considered as storage concept for surplus generated energy during sunny or windy times. However, efforts to store energy through the conversion of carbon-containing gases experience the same problems that are already known from conventional processes, including carburization in low oxygen partial pressure atmospheres, as they occur in energy technology, chemical engineering, and petro chemistry [1-4]. The extremely aggressive form of high-temperature corrosion "metal dusting" (MD) causes a spontaneous and fast degradation of metallic material [5-7]. Metal dusting occurs at temperatures between 450 and $800{ }^{\circ} \mathrm{C}$, the greatest risk being at around $620^{\circ} \mathrm{C}$ [7] and is characterized by a high carbon ingress into the material followed by graphite formation in the microstructure. This graphite formation leads to a large increase in volume and consequently to disintegration $[8,9]$. The attack is characterized by local, extremely fast-growing $\mathrm{Fe}-$, $\mathrm{Ni}$-, or $\mathrm{Co}$-based corrosion products [5]. In the case of Ni-based alloys, the material decomposes into dusty graphite ("metal dust") of metal particles, oxides, carbides, graphite, and amorphous carbon, which all together form a coke deposit [2]. Often, small component areas are affected, especially in the downstream area or in the area of heat exchangers, where the process temperature drops, as well as at inlets and outlets, transition pieces and colder flanges, where the critical conditions for metal dusting are locally fulfilled [10-12]. Thermodynamically, gases containing CO are unstable at lower temperatures. Favored by the catalytic effect of the elements iron, nickel, and cobalt, the $\mathrm{CO}$ dissociates and $\mathrm{C}$ is deposited on the surface and within the material [13]. Metal dusting is particularly dangerous because it is hardly possible to predict when and where damage will occur. In addition, a started metal dusting attack can no longer be stopped and causes severe damage in a relatively short period of time, leading to rapid system failure.

On the material side, there are currently two approaches to enhance the protection against metal dusting. (1) High-alloyed materials are used, which contain large amounts of oxide-forming elements, such as chromium and aluminum [14, 15]. The durability of these materials under strongly carburizing conditions is due to the formation of dense and slow-growing oxide layers, which protect the base material by forming a barrier from the corrosive atmosphere. These materials include the Ni-base alloys Alloy 602 CA, Alloy 690 or the particularly resistant Alloy 693 [15-18].

(2) Small additions of the elements $\mathrm{Sn}, \mathrm{Ge}$, and $\mathrm{Cu}$ have proven effective to catalytically suppress C deposition [5, 19-21]. While Ge and Sn are only used in coatings $[19,20]$, there are some commercial high-temperature materials that have taken up the concept by adding $\mathrm{Cu}$. Nishiyama et al. [22] claimed from a study on metal dusting of binary $\mathrm{NiCu}$ alloys with a $\mathrm{Cu}$ concentration of at 
least $20 \mathrm{wt} \%$, the surface reaction with the CO-containing synthesis gas is inactivated, and thus the material is protected from metal dusting, although no protective oxide layer has formed [23]. This behavior is attributed to the atomistic interaction of $\mathrm{CO}$ with the surface of the transition metal and is referred to as the "surfactant-mediated suppression" effect [22, 23]. Examples are the Ni-based materials Haynes 235 and the Sumitomo Alloy 696 with $\mathrm{Cu}$ contents between 2 and $4 \mathrm{wt} \%$ beside high $\mathrm{Cr}$ concentrations (around $30 \mathrm{wt} \%$ ), which additionally improves the resistance against metal dusting. However, alloys solely protected by metal-dusting-inhibiting elements for these specific applications have not been deeply investigated and developed so far. NiCu alloys, such as so-called Monel materials, with significantly higher $\mathrm{Cu}$ contents of $>30 \mathrm{wt} \%$ and low amounts of oxide formers are promising candidates.

\section{Experimental Procedures}

\section{Powder Production of Monel and NiCu Alloys by Gas Atomization}

In the present study, the material was gas-atomized using an Indutherm AU3000 atomizer in close-coupled mode. In a ceramic crucible, the initial material is melted inductively at $1650{ }^{\circ} \mathrm{C}$. After complete melting and a defined holding time of $30 \mathrm{~min}$, the melt is introduced into the atomizer nozzle through an outlet valve and atomized under Ar at a pressure of 12 bar and a flow of $360 \mathrm{~m}^{3} / \mathrm{h}$ in close-coupled mode [24]. The cooling rate is between $10^{5}$ and $10^{8} \mathrm{~K} / \mathrm{s}$ during gas atomization [24]. After the atomization, the powder was sieved with a $63 \mu \mathrm{m}$ sieve to remove the coarse fraction and then air-separated to remove the fine fraction with a particle size of less than $10 \mu \mathrm{m}$. The particle size distribution was investigated according to ISO 13322-2 using a Mictrotrac Camsizer X2. Powders were produced for Monel Alloy 400, and binary CuNi alloys with $70 \mathrm{wt} \% \mathrm{Ni}(\mathrm{Ni} 70-\mathrm{Cu} 30)$ and $50 \mathrm{wt} \% \mathrm{Ni}$ (Ni50-Cu50), respectively.

\section{Additive Manufacturing of Monel and NiCu Alloys by Laser Powder Bed Fusion (LPBF)}

In laser powder bed fusion (LPBF), multi-layer micro-welding processes are used to generate macroscopic structures: The material to be processed is applied in powder form with particle sizes of approx. 10-60 $\mu \mathrm{m}$ in a thin layer $(20-100 \mu \mathrm{m})$ on a component platform and completely remolten locally using laser radiation. After solidification, a solid layer of material forms. The component platform is then lowered by the amount of a layer thickness and powder is applied again. The process parameters include the laser power, the laser feed speed, the layer height, and the hatching distance, i.e., the distance between the individual melt tracks. It affects the density and surface of the component. If the distance is too large, the traces are not molten completely, and the component becomes porous. The quality of the melting tracks is influenced by the laser power and the laser speed. The width of the 
melting traces depends on the focus diameter of the laser [8]. In this study, a laser power of $250 \mathrm{~W}$, a feed rate of $800 \mathrm{~mm} / \mathrm{s}$, a layer thickness of $20 \mu \mathrm{m}$, and a hatching distance of $0.1 \mathrm{~mm}$ were used for the additively manufactured sample. Cubic samples with $0.8 \times 0.8 \times 0.8 \mathrm{~cm}$ were generated. After printing, one sample is exposed in as-built condition, and the other one out of two comparable samples was ground, using SiC paper with up to P1200 grit before exposure. In addition, one conventional manufactured Monel Alloy 400 (cast and rolled) is included into the metal dusting experiments.

\section{Metal Dusting Exposure}

The metal dusting exposure testing was conducted in a tube furnace (Carbolite TZF12/100/900/E301) equipped with an Centralloy ET 45 Micro tube and an inside mullite tube. For further information on the furnace and gas setup of these tests, it is referred to [25]. Before starting the exposure, the furnace was purged with argon for several hours at room temperature and was subsequently heated up to $620{ }^{\circ} \mathrm{C}$ with a heating rate of $10 \mathrm{~K} / \mathrm{min}$. At process temperature, a gas composition of $20 \%$ $\mathrm{CO}-20 \% \mathrm{H}_{2}-1 \% \mathrm{H}_{2} \mathrm{O}-8 \% \mathrm{CO}_{2}-51 \%$ Ar was adjusted, and the system was pressurized to 18 bar. The $\mathrm{C}$ activity is $a_{\mathrm{c}}=358$ (calculated as described for the synthesis gas reaction in chapter 9.2 of [26]) according to $a_{C}=K \frac{p_{\mathrm{H}_{2}} p_{\mathrm{CO}}}{p_{\mathrm{H}_{2} \mathrm{O}}} . K$ is the equilibrium constant of the syngas reaction, $p_{\mathrm{H}_{2}}, p_{\mathrm{CO}}$, and $p_{\mathrm{H}_{2} \mathrm{O}}$ the partial pressures of $\mathrm{H}_{2}, \mathrm{CO}$, and $\mathrm{H}_{2} \mathrm{O}$, respectively. The remaining oxygen partial pressure is $1.7 \times 10^{-23}$ bar in thermodynamic equilibrium (calculated using Factsage ${ }^{\circledR}$ ). During the isothermal exposure, a gas flow of $7.5 \mathrm{l} / \mathrm{h}$ is used. For separation of the specimens during the exposure, the samples were positioned in $\mathrm{Al}_{2} \mathrm{O}_{3}$ crucibles one by one. After each $240 \mathrm{~h}$, the furnace was cooled with no defined rate in Ar atmosphere, the samples were investigated, and the coke was removed from the samples using a brush. They were cleaned for $10 \mathrm{~min}$ in ethanol and subsequently $10 \mathrm{~min}$ in water in an ultrasonic bath, rinsed with acetone, and dried. The samples were photo-documented and weighed using a precision weighing balance (Mettler Toledo XP205) with a resolution of $0.05 \mathrm{mg}$ before introducing them back into the furnace. The experiment was conducted for up to $960 \mathrm{~h}(4 \times 240 \mathrm{~h})$.

\section{Metallographic Preparation and Investigations}

The surface roughness of the samples before exposure was measured by optical 3D roughness analyzation using a Nanofocus $\mu$ surf P200 confocal laser system. The optical density of the LPBF samples before exposure was measured according to VDI 3405-2 for five images on three cross sections perpendicular to the building direction. The alloy composition was measured by electron probe microanalysis (EPMA Jeol JXA-8100) equipped with a WDX-detector for qualitative and quantitative measurements. The $\mathrm{C}$ concentration was measured by an Agilent 5800 ICP-OES as the quantitative measurement of $\mathrm{C}$ concentration using WDX is difficult because $\mathrm{C}$ can be deposited under the electron beam. 
After $960 \mathrm{~h}$ exposure, the samples were half-sectioned parallel to their building direction. One halves of the samples were used for surface investigations using highresolution scanning electron microscopy (SEM, Zeiss Auriga) system with SESI (Secondary Electrons Secondary Ions) detector in combination with energy-dispersive X-ray spectroscopy EDS (Oxford Systems). The other halves were coated with a Ni plating to avoid damage of the corrosion products and mounted face down into epoxy resin, subsequently ground with $\mathrm{SiC}$ papers, and polished using diamond suspension up to a surface finish of $1 \mu \mathrm{m}$. The cross sections were used to investigate the corrosion products with a focus on the subsurface zone and the samples microstructures using optical microscopy and EPMA. For thickness determinations of the corrosive zone, five measurements per side were taken.

\section{Results}

\section{Powder Particles and As-Built LPBF Materials}

The gas-atomized powder particles exhibit a spherical shape without pore formation (not shown here). The particle size distribution reveals a median diameter $d(0.5)$ of $42.05 \mu \mathrm{m}$ for Monel Alloy 400, a $d(0.5)$ of $44.12 \mu \mathrm{m}$ for Ni70-Cu30, and a $d(0.5)$ of $43.56 \mu \mathrm{m}$ for Ni50-Cu50 (particle size distributions not shown here). It has to be mentioned that all compositions exhibited particle size distributions suitable for LPBF.

SEM micrographs are shown in Fig. 1 for the as-built samples generated by LPBF of Monel Alloy 400 (see Fig. 1a), the Ni70-Cu30 (see Fig. 1b), and the Ni50-Cu50 binary alloy (see Fig. 1c). All samples are single $\alpha-(\mathrm{Ni}, \mathrm{Cu})$ phase after printing (EDS and EBSD measurements not shown here). The LPBF-built samples exhibit relative optical densities of $99.8 \% \pm 0.2 \%$ and do not show significant pore formation. Furthermore, elongated grains in building direction are visible. The surface roughness of the LPBF samples has $R_{a}$ values of $3.9 \mu \mathrm{m} \pm 0.7 \mu \mathrm{m}$ on the top and $10.5 \mu \mathrm{m} \pm 0.6 \mu \mathrm{m}$ on the side surfaces of all investigated samples, which is approximately one order of magnitude higher than the ground sample with an $R_{a}$ value of $0.3 \mu \mathrm{m} \pm 0.1 \mu \mathrm{m}$ on all sides.

All investigated alloy compositions measured by EPMA are listed in Table 1. Using $11 \times 11$ quantitative point measurements with a distance of $1 \mu \mathrm{m}$ in the samples center, the sample's homogeneity is investigated. Concentration deviations are added to Table 1 in form of measurement errors. The $\mathrm{C}$ concentration as measured by ICP-OES has a value of $0.13 \mathrm{wt} \%$ for Monel Alloy 400. No contamination or deviation of Monel Alloy 400 from the standard composition according to DIN 17743 is visible. 
Fig. 1 SEM micrographs (SESI) of the initial microstructure parallel to their building direction (BD) before exposure: a as-built LPBF sample of Monel Alloy 400, b as-built LPBF sample of binary Ni70-Cu30 alloy, $\mathbf{c}$ as-built LPBF sample of binary Ni50-Cu50 alloy
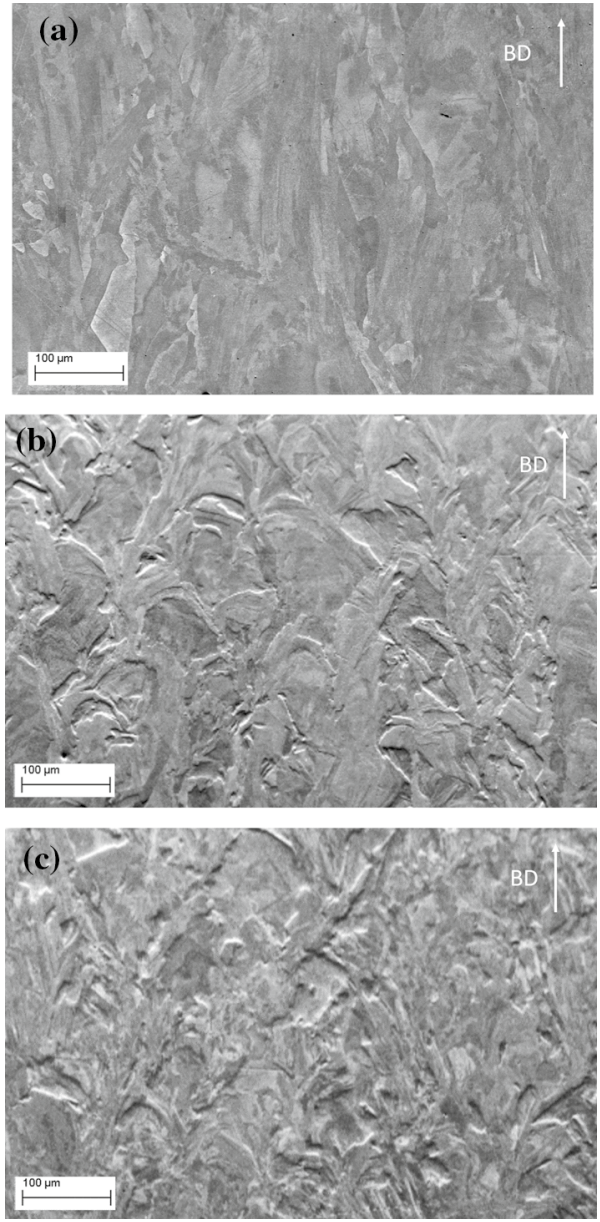

Table 1 Chemical composition (in wt \%) of the investigated technical and binary NiCu alloys by EPMA

\begin{tabular}{lllllll}
\hline Alloy & $\mathrm{Ni}$ & $\mathrm{Cu}$ & $\mathrm{Al}$ & $\mathrm{Fe}$ & $\mathrm{Mn}$ & $\mathrm{Si}$ \\
\hline Monel LPBF & $67.00 \pm 0.44$ & $29.85 \pm 0.32$ & $0.18 \pm 0.01$ & $2.15 \pm 0.06$ & $1.16 \pm 0.03$ & $0.27 \pm 0.02$ \\
Ni70-Cu30 LPBF & $72.48 \pm 0.63$ & $28.95 \pm 0.72$ & - & - & - & - \\
Ni50-Cu50 LPBF & $54.11 \pm 0.70$ & $47.89 \pm 0.70$ & - & - & - & - \\
\hline
\end{tabular}

\section{Metal Dusting Tests: Mass Changes}

In order to quantify the resistance of binary $\mathrm{Ni}-\mathrm{Cu}$ alloys compared to Monel Alloy 400, the alloys listed in Table 1, and a cast and ground (P1200 grit) benchmark sample were exposed to metal dusting conditions. To consider the effect of the 

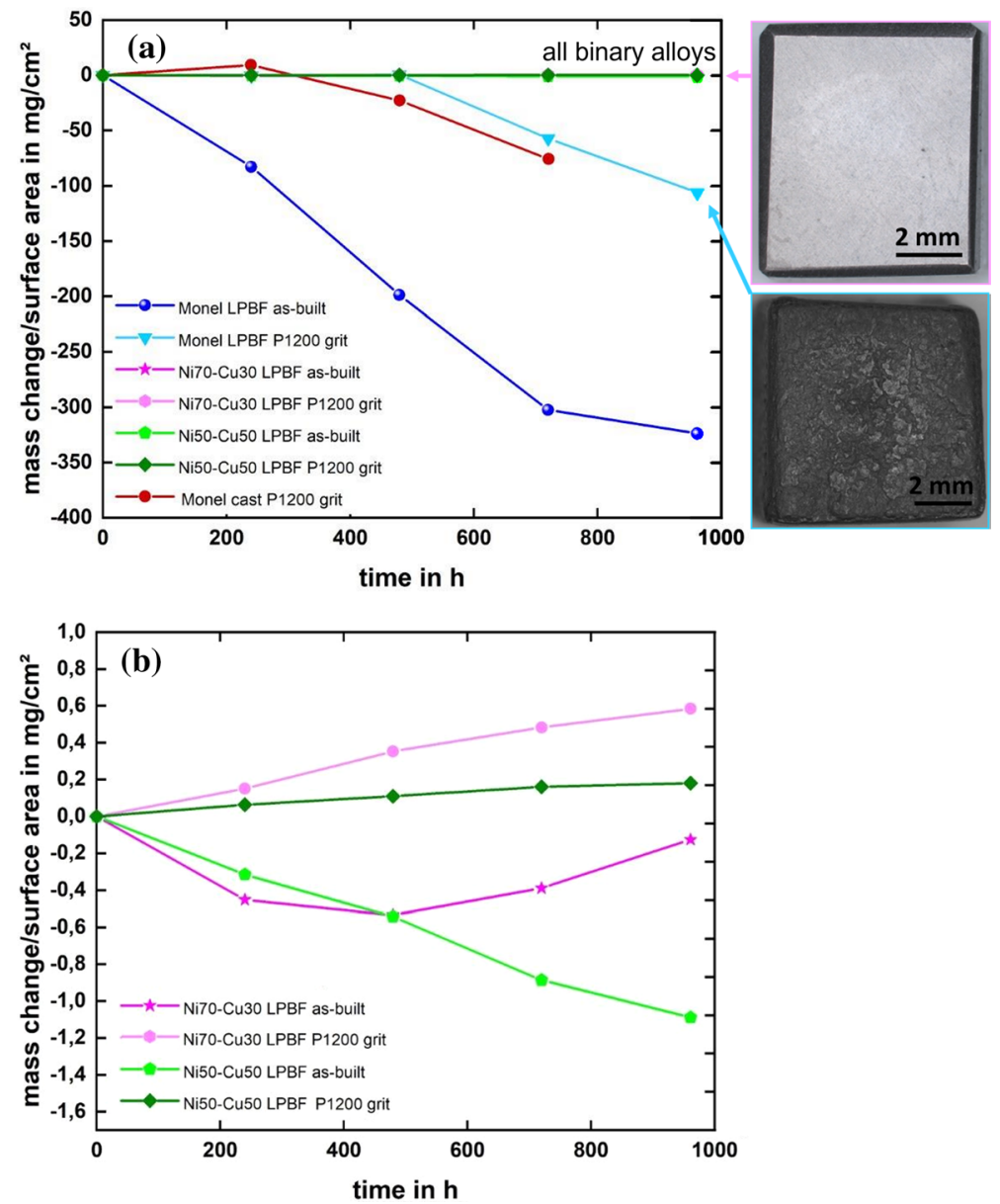

Fig. 2 Net mass changes over exposure in $20 \% \mathrm{CO}-20 \% \mathrm{H}_{2}-1 \% \mathrm{H}_{2} \mathrm{O}-8 \% \mathrm{CO}_{2}-51 \%$ Ar at $620{ }^{\circ} \mathrm{C}$ and 18 bar for $960 \mathrm{~h}$ : a all investigated samples with binary alloys positioned at the zero line, b higher magnification with binary alloys only. In (a), an optical micrographs of the Ni70-Cu30 LPBF (above) and the Monel LPBF (below) samples (P1200 grit surface finish) after $960 \mathrm{~h}$ exposure are added (Color figure online)

surface roughness, the samples were exposed in (1) as-built condition and in (2) a P1200 grit surface finish. The mass changes, surfaces, and corrosion products were investigated.

The respective net mass changes for all alloys during exposure are shown in Fig. 2a. As the mass changes for the binary alloys are very low, the results are presented on a smaller scale in Fig. 2b. Considering Fig. 2a, it is obvious from the mass change characteristics and the micrographs of the samples, that the LPBF Monel samples show a much higher mass loss (up to four orders of magnitude) 

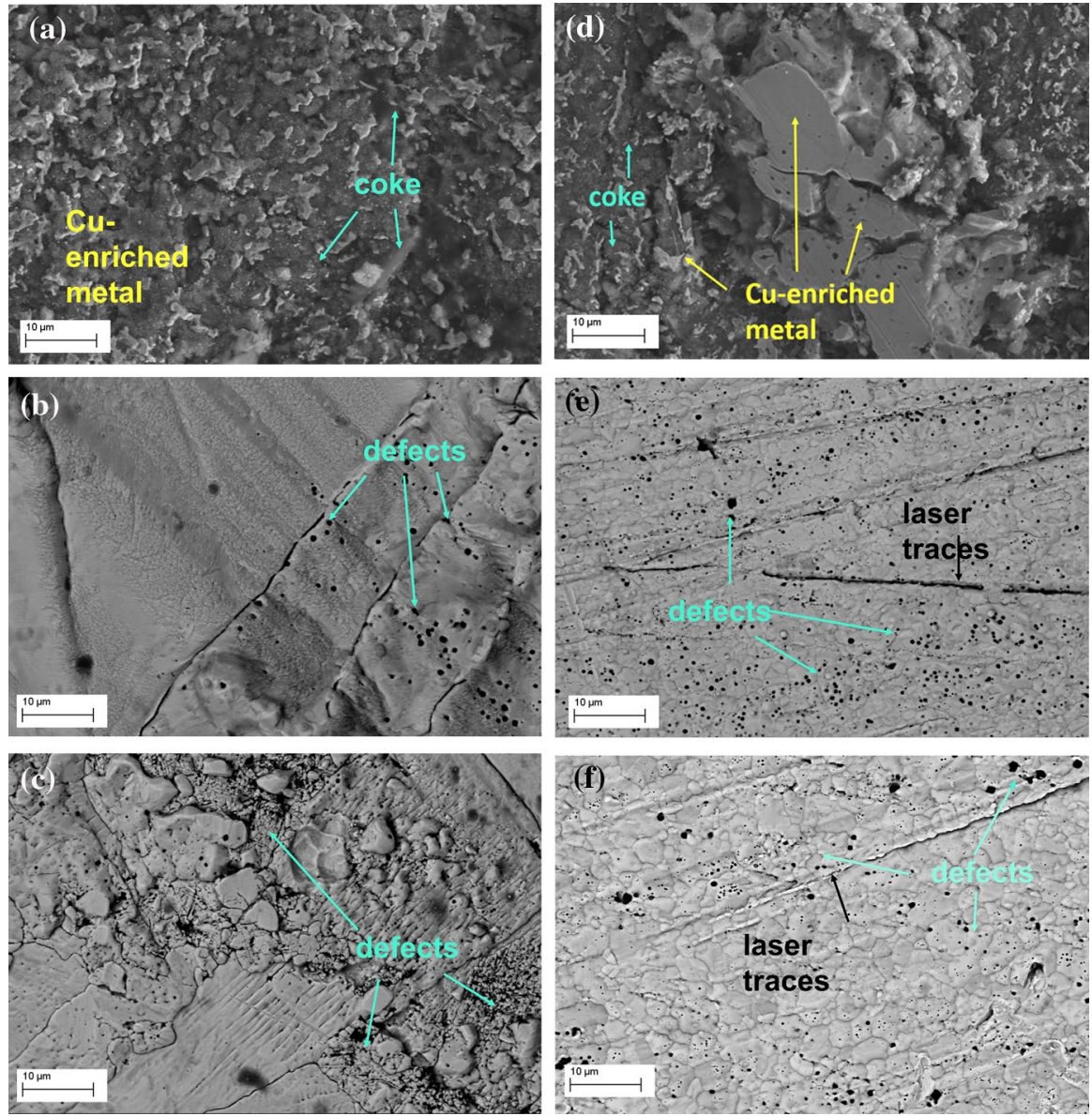

Fig. 3 SEM micrographs (SESI) of the surfaces after exposure in 20\% CO-20\% $\mathrm{H}_{2}-1 \% \mathrm{H}_{2} \mathrm{O}-8 \%$ $\mathrm{CO}_{2}-51 \%$ Ar at $620{ }^{\circ} \mathrm{C}$ and 18 bar for $960 \mathrm{~h}$ : a Monel LPBF as-built, b binary Ni70-Cu30 LPBF asbuilt, $\mathbf{c}$ binary Ni50-Cu50 LPBF as-built, d Monel LPBF P1200 grit, e binary Ni70-Cu30 LPBF P1200 grit, f binary Ni50-Cu50 LPBF P1200 grit

due to massive metal dusting attack in comparison to the binary systems. The Monel cast and the LPBF P1200 grit sample show a comparable net mass change. Compared to these two samples, the as-built Monel LPBF sample showed a three times higher mass loss. The as-built binary alloys exhibit small mass losses followed by a mass gain after $480 \mathrm{~h}$ in the case of the Ni70-Cu30 LPBF sample, see Fig. 2b. For the surface-finished binary alloys, however, very low mass gains below $0.55 \mathrm{mg} / \mathrm{cm}^{2}$ are visible for the examined exposure time. To summarize, a significant difference between the technical Monel Alloy 400 and the binary alloys was found. 


\section{Surface Investigations After $960 \mathrm{~h}$ of Exposure Time}

In Fig. 3, the corrosion product formation at the surface is shown for all investigated alloys. Regarding the Monel Alloy 400 LPBF as-built sample, coke formation at the surface is occurring with small metallic protrusions of $\mathrm{Ni}$ and $\mathrm{Cu}$ with diameters below $3 \mu \mathrm{m}$, see Fig. 3a. In contrast to this, larger $\mathrm{Ni}-\mathrm{Cu}$ areas with sizes above $20 \mu \mathrm{m}$ are visible for the Monel Alloy 400 LPBF P1200 grit sample, see Fig. 3d. However, both samples suffer from a significant coke formation. For the as-built (Fig. 3b, c) and ground (Fig. 3e, f) binary NiCu alloys, small dark areas at the surface probably represent surface defects or coke. The overlap of the laser traces, given by dark lines in the Figures for the binary alloys, belong to the scanning strategy of the laser system and are still visible after exposure. For all samples of the binary $\mathrm{NiCu}$ LPBF samples in both surface finish states, no significant surface degradation occurs after $960 \mathrm{~h}$ of exposure.

\section{Corrosion Products After 960 h of Exposure Time}

In Fig. 4, EPMA back scattering electron (BSE) images and corresponding element distribution maps are shown for all investigated samples after $960 \mathrm{~h}$ exposure, in asbuilt and ground condition, respectively. Regarding the LPBF Monel alloy, a severe degradation of the surface is visible, samples in Fig. 4a and d. In the as-built condition, graphite (coke) formation, which was verified by Raman measurements (not shown here), is visible, and the penetration depth has a value of $205 \pm 26 \mu \mathrm{m}$. In the coke, $\mathrm{Cu}$-enriched metallic residues were found, which consist of $65.38 \pm 3.43 \mathrm{wt} \%$ $\mathrm{Ni}, 33.15 \pm 2.90 \mathrm{wt} \% \mathrm{Cu}, 0.90 \pm 0.81 \mathrm{wt} \% \mathrm{Mn}, 1.79 \pm 0.29 \mathrm{wt} \% \mathrm{Fe}, 0.12 \pm 0.07 \mathrm{wt} \%$ $\mathrm{Al}, 0.24 \pm 0.22 \mathrm{wt} \% \mathrm{Si}$. Hence, based on measurements of the original alloy composition (compare Table 1), the concentration of $\mathrm{Cu}$ in this region is increased by $3.3 \pm 2.9 \mathrm{wt} \%$. From the oxygen element distribution map, it is obvious that these $\mathrm{Cu}$-enriched areas consist of pure metal and no oxides are formed here. The $\mathrm{O}$-enriched areas found in the reaction zone rather overlap with dark areas in the BSE-image. O-enrichment is either found close to the sample surface (marked in red in Fig. 4a) where sufficiently big holes have formed in the reaction zone to accommodate remains of the sample preparation process ( $\mathrm{SiC}$ papers were used). On the other hand, O-enriched areas are located close to the remaining metallic substrate (marked in white in Fig. 4a) and rather appear to be an oxide which composition has to be further investigated in future. Grinding of the sample surface leads to a decrease of the penetration depth to $158 \pm 38 \mu \mathrm{m}$. However, for both samples the formation of coke was observed in a similar way. A different behavior becomes obvious when regarding the binary alloys. Here, a near-surface attack by carbon penetration is occurring. In the case of the Ni70-30Cu and Ni50-50Cu LPBF as-built sample, an MD-affected subsurface zone with a depth of $33 \pm 13 \mu \mathrm{m}$ and $17 \pm 15 \mu \mathrm{m}$, respectively, was identified (cf. Fig. 4b, e). In the upper region, carbon is detected in the grain volume whereas in deeper regions only grain boundaries are affected. The samples which received a surface finish showed much less and only local carbon incorporation, without pronounced grain boundary attack (Fig. 4c, f). Comparing 
(a)
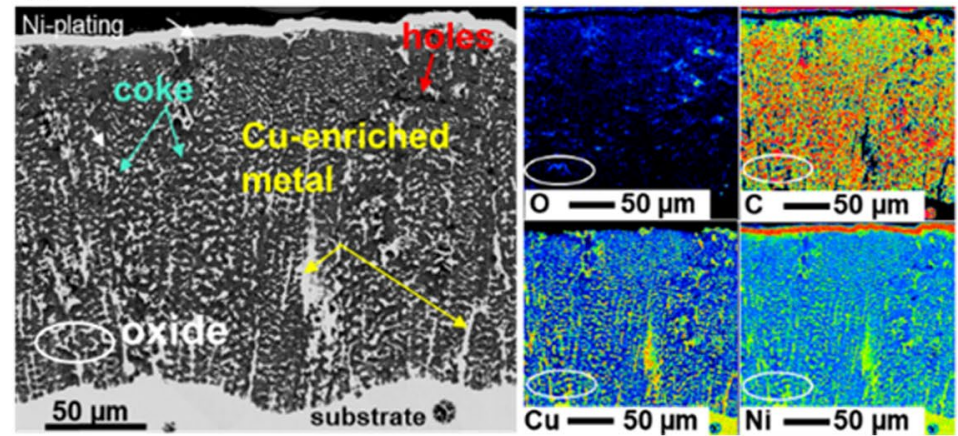

(b)

(c)
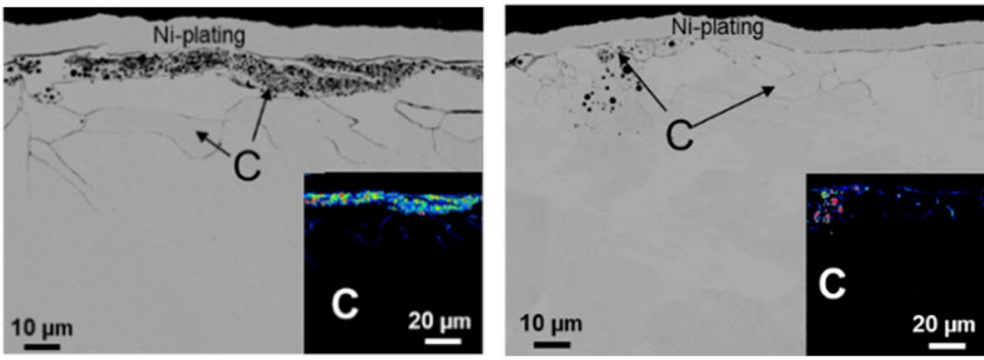

(d)

(e)
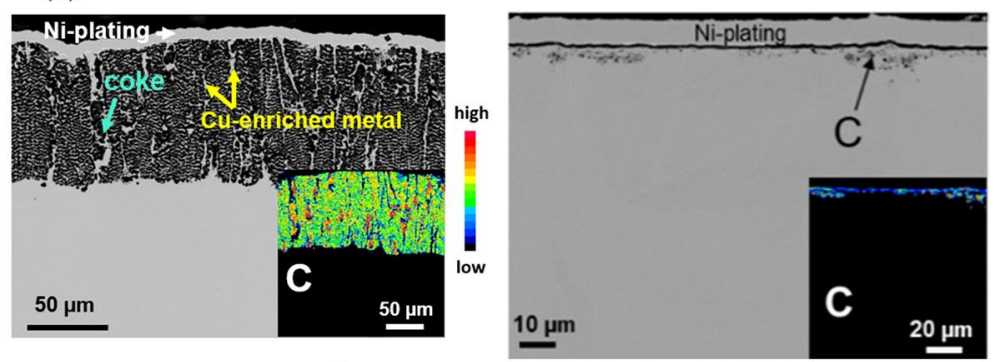

(f)

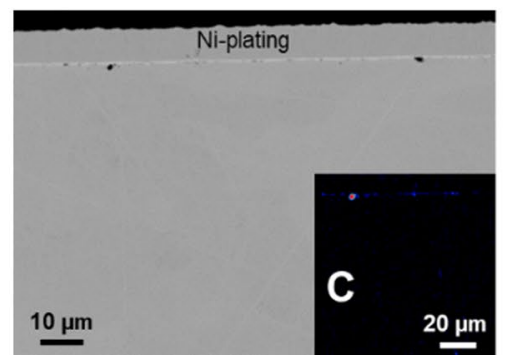

Fig. 4 EPMA BSE images and selected EPMA element maps of cross sections of Monel Alloy 400 LPBF and binary NiCu LPBF alloys after exposure in $20 \% \mathrm{CO}-20 \% \mathrm{H}_{2}-1 \% \mathrm{H}_{2} \mathrm{O}-8 \% \mathrm{CO}_{2}-51 \% \mathrm{Ar}$ at $620{ }^{\circ} \mathrm{C}$ and 18 bar for $960 \mathrm{~h}$ : a Monel LPBF as-built, b Ni70-Cu30 LPBF as-built, c Ni50-Cu50 LPBF as-built, d Monel LPBF P1200 grit, e Ni70-Cu30 LPBF P1200 grit, f Ni50-Cu50 LPBF P1200 grit (Color figure online) 
the different alloy compositions, the MD attack seems to be less severe in the case of Ni50-50Cu than for Ni70-30Cu and in both cases significantly less than for the Monel Alloy 400 LPBF sample.

Besides the LPBF samples, a cast microstructure was investigated as a reference. Figure 5a shows the initial, coarse-grained microstructure of the cast and ground (P1200 grit) Monel Alloy 400 sample prior to exposure. The exposed sample, see Fig. 5b, suffers from a surface degradation due to metal dusting and the formation of coke with a reaction zone thickness of $125.44 \pm 40.19 \mu \mathrm{m}$. The metal-dustingattacked areas are interrupted by unaffected surface patches, see magnified area in Fig. 5b. Furthermore, when looking at the interface between the attacked scale and the metal underneath, it becomes obvious that the attack follows the structure of the large grains and is rather uneven. Instead, the finer-grained structure with elongated grains along the building direction of the LPBF sample leads to the homogeneous corrosion front shown in Fig. 4a and d.

\section{Discussion}

The mechanism of metal dusting in Ni alloys is commonly described as follows: (1) C-containing gas molecules dissociate at the alloy surface, (2) $\mathrm{C}$ atoms accumulate at the alloy surface and form coke, (3) while dissolving into the metallic material, (4) followed by supersaturation and nucleation of graphite on defects or preferential crystal orientations, (5) to finally growth of graphite and disintegration of the alloy [5]. In this work, none of the investigated alloys formed a surface oxide scale to protect the underlying substrate material from degradation. Even though the subsurface zone in Monel Alloy 400 exhibited a so-called zebralike structure, comparable to [27], the mechanism differs by forming alternating coke and slightly $\mathrm{Cu}$-enriched metal layers instead of oxide layers with graphite and metal layers. The reason is the lack of high amounts of oxide formers and thus scale forming stable oxides at $p\left(\mathrm{O}_{2}\right)=1.7 \times 10^{-23}$ bar in the alloy (for comparison at $620{ }^{\circ} \mathrm{C} \mathrm{NiO}$ forms up from $p\left(\mathrm{O}_{2}\right)=10^{-20}$ bar and $\mathrm{Cu}_{2} \mathrm{O}$ up from around $10^{-14}$ bar [11]). The observed MD resistance of the investigated alloys is related to $\mathrm{Cu}$, which becomes obvious when comparing both binary alloys (see Fig. 4). Besides the MD-inhibiting effect $\mathrm{Cu}$ has on $\mathrm{CO}$ dissociation, another mechanism to mitigate the $\mathrm{MD}$ attack could be the reduction of $\mathrm{C}$ diffusion in the alloy. However, addition of $\mathrm{Cu}$ does not affect the $\mathrm{C}$ diffusion rate, which was shown in [28, 29]. Nishiyama and Otsuka investigated the role of $\mathrm{Cu}$ in binary $\mathrm{NiCu}$ alloys and claimed that the dissociation of $\mathrm{CO}$ molecules adsorbed on the metal surface is suppressed, when the $\mathrm{Cu}$ content exceeds $20 \mathrm{wt} \%$ within the alloy [22] by considering the electronic structure of transition metals [23]: an upward shifting of the Fermi level in the d-band state due to electron donor elements is supposed to be the key factor for metal dusting resistance, and a completely filled d-band with electrons is assumed to be necessary to prevent metal dusting phenomena without oxide scales. Additionally, $\mathrm{Cu}$ was found to segregate to surface sites rather than bulk sites in earlier studies [30], which should enhance the inhibiting effect [5, 
Fig. 5 a SEM micrograph of the initial microstructure prior to exposure of a cast and ground sample of Monel Alloy 400, b optical micrograph and EPMA BSE image of a cast and ground Monel Alloy 400 after exposure to $20 \% \mathrm{CO}-20 \% \mathrm{H}_{2}-1 \%$ $\mathrm{H}_{2} \mathrm{O}-8 \% \mathrm{CO}_{2}-51 \%$ Ar at $620^{\circ} \mathrm{C}$ and 18 bar for $720 \mathrm{~h}$
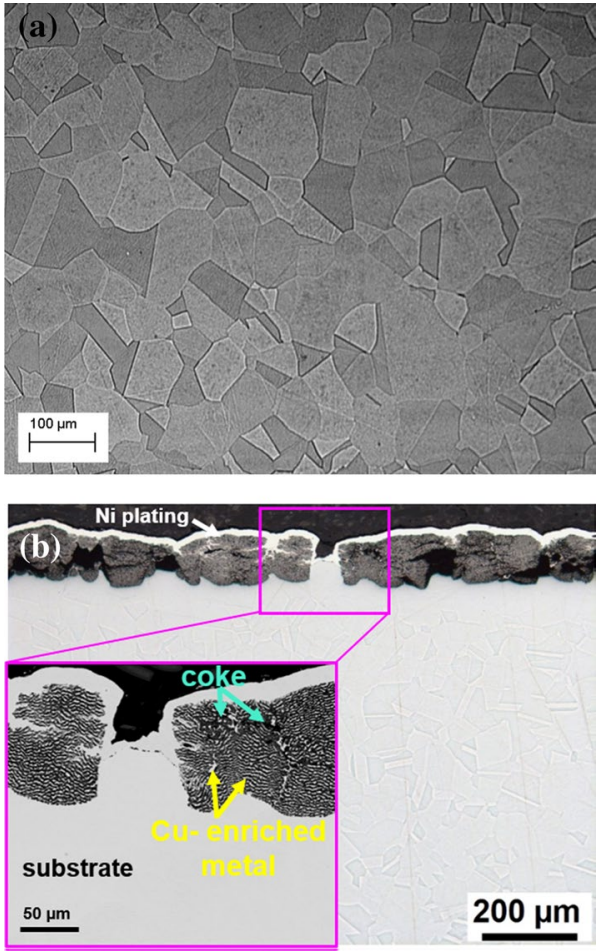

23]. However, in contrast to the expectations based on the findings of Nishiyama et al., the binary $\mathrm{NiCu}$ alloys and the technical Monel Alloy 400 showed no complete protection against metal dusting, even though all investigated alloys in this study exhibit a $\mathrm{Cu}$ content higher than $20 \mathrm{wt} \%$. Compared to the earlier investigations, a 10 times longer exposure time was chosen in this study as well as a 10 times higher $\mathrm{C}$ activity $\left(a_{\mathrm{C}}=358\right.$ in the present study and $a_{\mathrm{C}}=31$ in [23] with respect of the equation given in [26]). Thus, the $\mathrm{CO}$ molecule dissociation cannot be fully suppressed but leads to both, a significant retardation and enhanced resistance as it was reported in the catalysis literature and previous investigations on metal dusting [31-33].

In contrast to the binary alloys, the metal dusting behavior of the technical Monel Alloy 400 highly differs. Although the $\mathrm{Cu}$ content in Monel Alloy 400 is comparable to the Ni70-30Cu system, pronounced coke formation and surface degradation was observed as shown in Fig. 4a, c. The cross section of the degraded zone in Fig. 4a and c shows that the alloy is disintegrated by the coke formation, and only small metallic residues are visible within the penetration zone. Therefore, the mass changes of the Monel alloys are negative, as beside $\mathrm{C}$ incorporation into the material causing mass gain as observed for the binary alloys, metal is lost by the formation of coke. The difference between the different metal dusting resistance of Monel Alloy 400 and the binary Ni70-30Cu might be due to further alloying elements of the technical Monel Alloy 400 (cf. Table 1). 
Oxide and carbide formers such as $\mathrm{Fe}, \mathrm{Mn}$, and Si might react with the CO-containing atmosphere and influence the surfactant mediated suppression effect negatively. As the effect relies on the electronic structure of the metal surface, even small imperfections or changes of the electronic structure at the surface might result in $\mathrm{CO}$ molecule dissociation, by graphite formation and finally material degradation by metal dusting.

It could be argued that the additively manufactured samples might show different microstructures or variations in composition over the alloy compared to conventionally manufactured alloys, which affects the metal dusting behavior. Regarding Fig. 1 and Table 1, the LPBF samples appear very homogenous. Additionally, the pronounced attack of the grain boundaries, as it is found for the binary alloys without surface finish (compare Fig. 4b, c), is in agreement with observations found elsewhere [34-37]. However, not only the $\mathrm{Cu}$ content and the microstructure but also the surface finish have to be considered. It was found that previous grinding (P1200 grit surface finish) of the additively manufactured samples (1) delays the time to mass loss in the case of the Monel alloy (Fig. 3b) and (2) decreases the penetration depth (Fig. 4). The binary alloy specimens regarded by Nishiyama and Otsuka in [22, 23] were ground using 600 grit paper and had a comparable surface roughness as the LPBF P1200 grit samples of this study. The as-built LPBF samples on the other hand exhibit a ten times higher surface roughness $(3.9 \mu \mathrm{m} \pm 0.7 \mu \mathrm{m}$ compared to $0.3 \mu \mathrm{m} \pm 0.1 \mu \mathrm{m})$ than the ground samples due to unmelted powder particles during LPBF, resulting in an increase in surface and near-surface defects such as small pores that occur due to the LPBF manufacturing process. These surface imperfections seem to have an influence on the metal dusting resistance. It has to be mentioned, that in case of the as-built alloys, a mass loss occurs during the exposure to reducing atmosphere which is associated with a change in color of the sample from reddish to metallic (not shown here). This is in contrast to the behavior of the previously ground samples which solely show a mass gain and no change of surface color. Hence, the surface condition of the additively built samples plays an important role. Grinding of the samples leads (1) to a reduction of the zone penetrated by coke formation, (2) a decrease of $\mathrm{C}$ deposition on the surface and therefore a reduction in dissociation of $\mathrm{C}$-containing molecules, and (3) a decrease of graphite formation at the grain boundaries. Furthermore, grinding may lead to surface-near defects like dislocations or distortions. These results clearly show that the effect of surface finish needs to be regarded when considering $\mathrm{NiCu}$ alloys for $\mathrm{CO}$-containing atmospheres. Another parameter that has to be considered is differences in the microstructure of additively and conventionally manufactured samples. In Fig. 5, the MD behavior of a cast Monel Alloy 400 is shown, which differs from the LPBF-built samples by showing an effect of the large grains on the coke formation. As shown in Fig. 2, the mass loss during MD of the cast material is close to that of the LPBF sample after receiving the same surface finish. However, the samples differ in the microstructure of the reaction zones: The lamellae formed on the cast material are comparably fine and mostly parallel to the reaction zone/substrate interface. In contrast to this, the similar fine lamellae formed on the LPBF sample is interrupted by bigger areas of remaining metal with a structure perpendicular to the 
substrate surface which reminds of former grain boundaries. The validation that these structures are former grain boundaries has to be part of future works.

\section{Conclusion}

In this study, the metal-dusting behavior of additively manufactured binary $\mathrm{Ni}-\mathrm{Cu}$ alloys with 30 and $50 \mathrm{wt} \% \mathrm{Cu}$, respectively, and the technical Monel Alloy 400 with a $\mathrm{Cu}$ content of $30 \mathrm{wt} \%$ were investigated under metal dusting conditions. The expected effect of a reduced corrosion attack by increasing $\mathrm{Cu}$ addition is confirmed, however, no complete suppression was found. The effectiveness of $\mathrm{Cu}$ addition is shown to be influenced by (1) the surface finish and (2) the addition of further alloying elements. Grinding of the samples after additive manufacturing reduces the corrosion attack, which was demonstrated by (1) a reduced $\mathrm{C}$ incorporation into the subsurface zone, (2) a lower mass loss, and (3) an incubation time in the case of the Monel alloy. The as-built binary model alloys showed a mass loss instead of a mass gain during initial exposure, which is attributed to reduction reactions since no spallation was observed. Surface imperfections, which were deposited on the surface during additive manufacturing, such as unmelted powder particles resulting in a higher surface roughness or impurities, or propably also induced by grinding are shown to have an influence on the carbon uptake. A huge difference in corrosion resistance is found by comparing the binary and the Monel alloys even though they have comparable microstructures and $\mathrm{Cu}$ contents. The effect is attributed to the further alloying elements in the Monel alloy, but the exact mechanism of such minor elements has to be investigated in more detail in the future.

Acknowledgements The financial support by the AiF under the number IGF Nr. $20904 \mathrm{~N}$ is gratefully acknowledged. The authors thank E. Berghof-Hasselbächer for metallographic sample preparation, Dr. G. Schmidt for EPMA measurements, M. Röhrig for technical support during the metal dusting experiments (all from DECHEMA-Forschungsinstitut), and R. Bappert (now at SLM Solutions Group) for the manufacturing of powders and LPBF samples.

Funding Open Access funding enabled and organized by Projekt DEAL. The project received financial support by the AiF under the number IGF Nr. 20904N.

Availability of data and material The data will be made available on request (data transparency).

Code availability Not applicable (software application or custom code).

\section{Declarartions}

Conflict of interest The authors declare that they have no conflict of interest.

Open Access This article is licensed under a Creative Commons Attribution 4.0 International License, which permits use, sharing, adaptation, distribution and reproduction in any medium or format, as long as you give appropriate credit to the original author(s) and the source, provide a link to the Creative Commons licence, and indicate if changes were made. The images or other third party material in this article are included in the article's Creative Commons licence, unless indicated otherwise in a credit line to the material. If material is not included in the article's Creative Commons licence and your intended use is not permitted by statutory regulation or exceeds the permitted use, you will need to obtain permission 
directly from the copyright holder. To view a copy of this licence, visit http://creativecommons.org/licen ses/by/4.0/.

\section{References}

1. D. Ulber, J. Bohle, C. Beyer, and U. Wolf, in Steam Reforming Technology User Conference, Labuan (MYS) (2007).

2. H. J. Grabke and M. Spiegel, Materials and Corrosion 54(10), 799 (2003).

3. C. M. Chun and T. A. Ramanarayanan, Corrosion Science 51, 2770 (2009).

4. H. J. Grabke and M. Spiegel, in Occurrence of Metal Dusting-Referring to Failure Cases in Corrosion by Carbon and Nitrogen: Metal Dusting, Carburisation and Nitridation (EFC 41), eds. H. J. Grabke and M. Schütze (Woodhead Publishing, Cambridge, 2007), pp. 90-102.

5. D. J. Young, J. Zhang, C. Geers, and M. Schütze, Materials and Corrosion 62(1), 7 (2011).

6. P. A. Lefrancois and W. B. Hoyt, Corrosion 19(10), 360 (1963).

7. R. Schneider, E. Pippel, J. Woltersdorf, S. Strauß, and H. J. Grabke, Steel Research 68(7), 326 (1997).

8. H. J. Grabke, E. M. Müller-Lorenz and M. Zinke, in Metal Dusting Behaviour of Welded Ni-Base Alloys with Different Surface Finishes in Corrosion by Carbon and Nitrogen: Metal Dusting, Carburisation and Nitridation (EFC 41), eds. H. J. Grabke and M. Schütze (Woodhead Publishing, Cambridge, 2007), pp. 59-75.

9. H. J. Grabke, E. M. Müller-Lorenz, S. Strauss, E. Pippel, and J. Woltersdorf, Oxidation of Metals 50(3/4), 241 (1998).

10. W. Bergmann, Werkstofftechnik 2, 4, (Carl Hanser Verlag München, Munich, 2009).

11. R. Bürgel, Handbuch Hochtemperatur-Werkstofftechnik, (Vieweg Verlagsgesellschaft, Braunschweig, 2001).

12. J. Xie, L. Davies, D. Eisenhawer, R. Saunders, and L. Benum, Metal dusting in the crossover piping system at a petrochemical plant, in Proceedings of NACE Corrosion (2012).

13. D. J. Young and J. Zhang, Journal of the Minerals. Metals and Materials Society 64(12), 1461 (2012).

14. C. G. M Hermse and H. van Wortel, Metal dusting: a relation between alloy composition and degradation rate, in Proceedings of Eurocorr 2008 (Edinburgh, 2008).

15. D. Röhnert, M. Schütze, and T. Weber, Performance of several nickel base alloys in metal dusting atmospheres, in Proceedings of Corrosion 2007 Conference \& Expo, NACE, Paper No. 07417, Nashville.

16. E. Schwab, A. Milanov, S. A. Schunk, A. Behrens, and N. Schoedel, Chemie Ingenieur Technik 87(4), 347 (2015).

17. A. Rouaix-Vande Put, K. A. Unocic, M. P. Brady, and B. A. Pint, Corrosion Science 92,58 (2015).

18. B. A. Baker, G. D. Smith, V. W. Hartmann, L. E. Shoemaker, and S. A. McCoy, Nickel-base material solutions to metal dusting problem, in Corrosion 2002, ed. NACE, (2002), pp. 1-16.

19. C. Geers, Inhibition of Coking and Metal Dusting on Conventional Alloys by Using a Nickel-Tin Intermetallic Coating. PhD thesis (RWTH Aachen University 2013).

20. C. G. M. Hermse and H. van Wortel, Applicability of Coatings to Control Metal Dusting, proceedings of NACE Corrosion 2009, Paper No. 09150.

21. J. Zhang, D. M. I. Cole, and D. J. Young, Materials and Corrosion 56(11), 756 (2005).

22. Y. Nishiyama and N. Otsuka, Materials Science Forum 522-523, 581 (2006).

23. Y. Nishiyama, K. Moriguchi, N. Otsuka, and T. Kudo, Materials and Corrosion 56(11), 806 (2005).

24. D. Schwenck, N. Ellendt, J. Fischer-Bühner, P. Hofmann, and V. Uhlenwinkel, Powder Metallurgy 60(3), 198 (2017).

25. S. Madloch, A. S. Dorcheh, and M. C. Galetz, Oxidation of Metals 89(3-4), 483 (2018).

26. D. J. Young, High Temperature Oxidation and Corrosion of Metals (Elsevier, Oxford, 2008).

27. J. Z. Albertsen, Ø. Grong, J. C. Walmsley, R. H. Mathiesen, and W. Van Beek, Metallurgical and Materials Transactions A 39(6), 1258 (2008).

28. J. Zhang, M. Safarzadeh, and D. J. Young, Oxidation of Metals 70(1-2), 15 (2008).

29. J. Zhang and D. J. Young, Corrosion Science 56, 184 (2012). 
30. M. J. Kelley and V. Ponec, Progress in Surface Science 11(3), 139 (1981).

31. C. A. Bernardo, I. Alstrup, and J. R. Rostrup-Nielsen, Journal of Catalysis 96(2), 517 (1985).

32. I. Alstrup, M. T. Tavares, C. A. Bernardo, O. Sørensen, and J. R. Rostrup-Nielsen, Materials and Corrosion 49(5), 367 (1998).

33. J. A. Dalmon and G. A. Martin, Journal of Catalysis 66(1), 214 (1980).

34. J. C. Nava Paz and H. J. Grabke, Oxidation of Metals 39, 437 (1993).

35. C. M. Chun, T. A. Ramanarayanan, and J. D. Mumford, Materials and Corrosion 50, 634 (1999).

36. J. Zhang and D. J. Young, Corrosion Science 49, 1496 (2007).

37. H. J. Grabke, R. Krajak, E. M. Müller-Lorenz, and S. Strauß, Materials and Corrosion 47, 495 (1996).

Publisher's Note Springer Nature remains neutral with regard to jurisdictional claims in published maps and institutional affiliations. 